\title{
A Study to Assess the Effectiveness of Structured Teaching Programme on Knowledge Regarding Utilization of Crash Cart Trolley among III-B.Sc. Nursing Students at Selected College Villupuram
}

\author{
S. Aruna ${ }^{1}$, Kalaimathy K. ${ }^{2}$, G.Sivasakthi Raman ${ }^{3}$, S.Sivasankari ${ }^{3}$, \\ E.Soundharya $^{3}$, P.Srinivasan ${ }^{3}$, A.Subalakshmi ${ }^{3}$, M.Subapradha ${ }^{3}$ \\ ${ }^{1}$ Associate Professor, Department of Medical Surgical Nursing, ${ }^{2}$ Nursing Tutor, ${ }^{3}$ Final Year Students, \\ E S College of Nursing Villupuram \\ Corresponding Author: Kalaimathy K.
}

\section{ABSTRACT}

Aim: To assess the effectiveness of structured teaching programme on knowledge regarding utilization of crash cart trolley among III -B.Sc Nursing students at selected college, Villupuram Objectives:

1. To assess the knowledge on utilization of crash cart trolley among III-year, B.Sc [N] students.

2. To evaluate the effectiveness of structured teaching programme on knowledge regarding utilization of crash cart trolley among III year, B.Sc [N] students.

3. To find the association between the post-test knowledge regarding utilization of crash cart trolley among III year, B.Sc [N] students with their selected sociodemographic variables.

Methodology: A Pre experimental design with pre-test and post-test without control group was undertaken from E.S College of nursing. The population of the study consists of B.Sc $(\mathrm{N})$ III Year students at E.S. College of nursing.

Results: The structured questionnaire was used to computed the data. The statistics shows the following results.

Level of knowledge in pre-test $80 \%$ of students having inadequate knowledge, $20 \%$ of students having moderate knowledge, $0 \%$ of students having adequate knowledge.

Level of knowledge in post-test $0 \%$ of students having inadequate knowledge, $10 \%$ of students having moderate knowledge, $90 \%$ of students having adequate knowledge.
There was significant with gender and source of information.

There was no association between age, previous academic year percentage, previous exposure to crash cart trolley.

Conclusion: The present study assessed the knowledge regarding crash cart trolley in pretest. After providing structured teaching programme on utilization of crash cart trolley there is a significant improvement on knowledge of students regarding crash cart trolley. The study assessed the knowledge among students and they are gained in knowledge about crash cart trolley. The study concluded that the structured teaching programme was effective in improving in the knowledge regarding crash cart trolley.

Keywords: Utilization of Crash Cart Trolley

\section{INTRODUCTION}

"People who are always taking care of their health are like misers who are hoarding a treasure which they have never spirit enough to enjoy".

\section{$\sim$ Laurence Sterne}

Emergency Nursing is a nursing specialty in which nurse's care for patients in the emergency or critical phase of their illness or injury. In contrast to practically every other specialty of nursing, in which a patient arrives with a diagnosis applied by a physician and the nurse must manage the patient's care according to that diagnosis, 
emergency nurses work with patients in whom a diagnosis has not yet been made and the cause of the problem is not known. Emergency nurses frequently contact patients in the emergency department before the patient sees a physician. In this situation, the nurse must be skilled at rapid, accurate physical examination, early recognition of life-threatening illness or injury, the use of advanced monitoring and treatment equipment, and in some cases, the ordering of testing and medication according to "advance treatment guidelines" or "standing orders" set out by the hospital's emergency physician staff. Emergency nurses most frequently are employed in hospital emergency departments, though they may also work in free-standing urgent care clinics.

Crash cart is a specially designed trolley, used for transporting and dispensing medicines and equipment at the emergency site for participating in life saving measures. Crash carts are located in the areas of patient care in case of a life-threatening occurrence. Physicians, nurses, pharmacists, and respiratory therapists must become familiar with the contents of this cart. It contains necessary equipment to handle an emergency. A crash cart is enabling healthcare providers to manage medical emergencies easily and confidently.

The cart is characterized by being easily movable and readily accessible into all sides of the cart for quickly viewing and removing equipment and drugs during a crisis. The first cardiac crash cart was created at Bethany Medical Center in Kansas City, Kansas. One of the doctor's fathers fabricated the first crash cart. It contains an Ambu-bag, defibrillator paddles, a bed board and endotracheal tubes. A crash cart or code cart (crash trolley in UK medical jargon) is a set of trays/drawers/ shelves on wheels used in hospital emergency rooms for transportation and dispensing of emergency medication/ equipment at site of medical/surgical emergency for life support protocols like Advanced Cardiac Life Support/Advance
Life Support (ACLS/ALS), Pediatric Advanced life Support [PALS] to potentially save someone's life.

The contents of a crash cart vary from hospital to hospital, but typically contain the tools and drugs needed to treat a person in or near cardiac arrest. These include but are not limited to:

- Monitor/defibrillators and suction devices

- Advanced Cardiac Life Support (ACLS) drugs such as Epinephrine, Atropine, Amiodarone, Lidocaine, Sodium bicarbonate, Dopamine, and Vasopressin

- First line drugs for treatment of common problems such as: Adenosine, Dextrose, Diazepam or Midazolam, Epinephrine, Naloxone, Nitroglycerin, and others

- Drugs for rapid sequence intubation: Succinylcholine or other paralytic agents like Pancuronium, a sedative drug such as Etomidate or Midazolam; endotracheal tubes and other intubating equipment

- Vascular access devices-Intra Venous (IV) Cannula, Drip sets [Micro and Macro], IV fluids [Normal Saline (NS), Lactated Ringer (RL), Hydroxyethyl starch

- Other drugs and equipment as chosen by the facility.

\section{Statement of the Problem}

"A study to assess the effectiveness of Structured teaching programme on knowledge regarding utilization of crash cart trolley among III year, B.Sc. [N] students at selected College Of Nursing, Villupuram'.

\section{Objectives}

$>$ To assess the knowledge on utilization of crash cart trolley among III-year, B.Sc $[\mathrm{N}]$ students.

To evaluate the effectiveness of structured teaching programme on knowledge regarding utilization of crash cart trolley among III year, B.Sc [N] students. 
$>$ To find the association between the post-test knowledge regarding utilization of crash cart trolley among III year, B.Sc [N] students with their selected socio-demographic variables.

\section{Hypothesis}

$\mathbf{H}_{1} \cdot$ There is a significant difference in pre test and posttest knowledge of Student nurses.

$\mathbf{H}_{2} \cdot$ There is a significant association between the demographic characteristics and the
Post-test knowledge of student nurses.

\section{MATERIAL AND METHODS}

A Pre experimental design with pre test and post- test without control group was undertaken from E.S College of nursing. The population of the study consists of B.Sc (N) III Year students at E.S. College of nursing.

\section{RESULT AND DISCUSSION}

A Comparison of Pre and Post-Test Level of Knowledge on Utilization of Crash Cart Trolley among III Year B.Sc Nursing Students

\begin{tabular}{|l|c|c|c|c|}
\hline \multirow{2}{*}{ Level Of Knowledge } & \multicolumn{2}{|c|}{ Pre-Test Score } & \multicolumn{2}{c|}{ Post-Test Score } \\
\cline { 2 - 5 } & Number & Percentage & Number & Percentage \\
\hline Adequate $(>76 \%)$ & 0 & 0 & 36 & $90 \%$ \\
\hline Moderate $(51-75 \%)$ & 8 & $80 \%$ & 4 & $10 \%$ \\
\hline Inadequate $(<50 \%)$ & 32 & $20 \%$ & 0 & 0 \\
\hline
\end{tabular}

Assessment of the Level of Knowledge Regarding Utilization of Crash Cart Trolley among B.Sc Nursing III Year Students with before and after Structured Teaching Programme

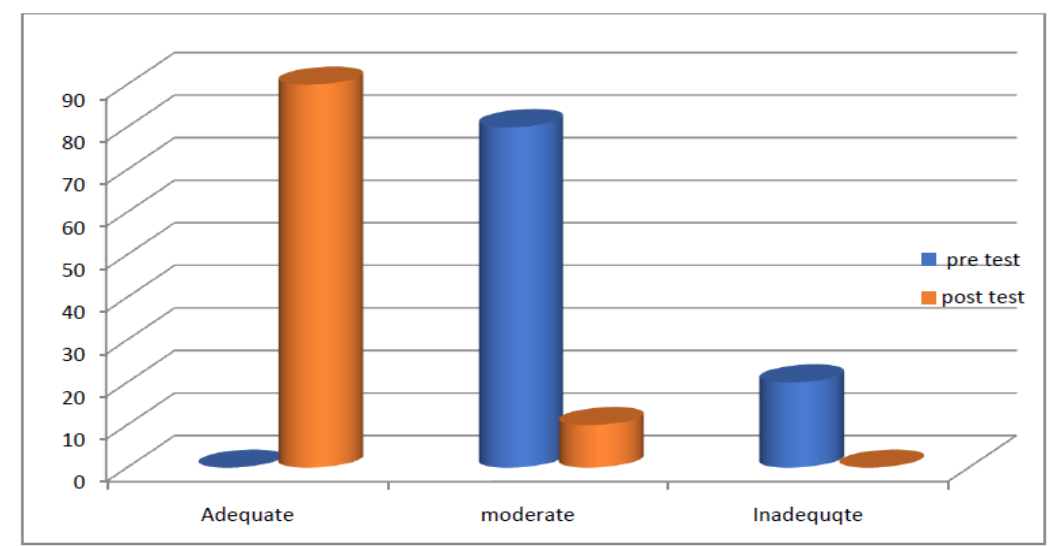

Fig: Assessment of the level of knowledge regarding utilization of crash cart trolley among B.Sc. nursing III year students with structured teaching programme.

\section{Effectiveness of Structure Teaching Programme on Knowledge Regarding Utilization of Crash Cart Trolley \\ Table 3.1.1: Effectiveness of structure teaching programme on knowledge regarding utilization of crash cart trolley}

\begin{tabular}{|c|c|c|l|c|c|}
\hline S.No. & Characteristics & Mean & Sd & Calculated Value & T-Value \\
\hline 1. & Pre-test & 8.425 & 2.011063 & 14.91 & 5.99 \\
\hline 2. & Post-test & 16.5 & 8.16123 & 2.39 & - \\
\hline \multicolumn{7}{c}{$\mathrm{P}<0.05^{*}=$ statistically significant }
\end{tabular}

Paired " $\mathrm{t}$ " test was done to assess the effectiveness of structured teaching programme on knowledge regarding crash cart trolley among B.Sc.(N) III-Year. The calculated value 2.39 was greater than the tabulated value 5.99 at $\mathrm{p}<0.05$ level. This shows that was a significant difference between the pre and post-test level of knowledge and regarding crash cart trolley. Hence structured teaching programme was effective in improving the knowledge regarding crash cart trolley among B.Sc.(N) III-Year students. 
Association between the Post-Test Knowledge Regarding Utilization of Crash Cart Trolley among B.Sc. Nursing III-Year Students with the Selected Demographic Variables

Table 4.1.1: Association between the post-test knowledge regarding utilization of crash cart trolley among B.Sc. Nursing III-Year Students with the selected demographic variables

\begin{tabular}{|c|l|c|c|c|}
\hline S.no. & \multicolumn{1}{|c|}{ Characteristic } & Frequency & Chi-square & T-value \\
\hline $\mathbf{1 .}$ & Age & & & \\
\hline & 18 & 1 & 5.57887 & 12.59 \\
\hline & 19 & 9 & $\mathrm{NS}$ & $\mathrm{DF}=6$ \\
\hline & 20 & 25 & & \\
\hline & 21 & 1 & & \\
\hline $\mathbf{2 .}$ & Gender & & & \\
\hline & Male & 5 & 0.63492 & 5.99 \\
\hline & Female & 35 & $\mathrm{~S}$ & $\mathrm{DF}=2$ \\
\hline $\mathbf{3 .}$ & Previous Year Academic Percentage & & & \\
\hline & $<50$ & 0 & 2.40602 & 12.59 \\
\hline & $51-60$ & 0 & $\mathrm{NS}$ & $\mathrm{DF}=6$ \\
\hline & 61.70 & 14 & & \\
\hline & $>71$ & 14 & & \\
\hline $\mathbf{4 .}$ & Previous Exposure To Crash Cart Trolley & & & \\
\hline & Yes & 26 & 2.39316 & 5.99 \\
\hline & No & 14 & $\mathrm{~S}$ & $\mathrm{DF}=2$ \\
\hline $\mathbf{5 .}$ & Source Of Information & & & \\
\hline & Books \& journals & 3 & 2.14815 & 12.59 \\
\hline & Mass media & 3 & $\mathrm{NS}$ & $\mathrm{DF}=6$ \\
\hline & Teacher's class & 3 & & \\
\hline & Clinical side & 31 & & \\
\hline
\end{tabular}

The above table shows that there is significant association between demographic variable are gender and previous exposure to crash cart trolley. And there is no significant association was found with other demographic variables such as age, Previous academic year \%, Source of information.

\section{DISCUSSION}

The aim of the study to assess the effectiveness of structured teaching programme on knowledge regarding utilization of crash cart trolley among B.Sc. [N] III-Year students in E.S. College of Nursing at Villupuram.

The pre experimental one pre-test and post-test design was adopted for this study and the number of sample is 40 .

With the reference of the objectives like age, gender, previous academic year percentage, previous exposure in using crash cart trolley, source of information.

The discussion was based on the objectives specified in this study:

$>$ To assess the knowledge on utilization of crash cart trolley among III year, B.Sc $[\mathrm{N}]$ students.
To evaluate the effectiveness of structured teaching programme regarding knowledge on utilization of crash cart trolley among III year, B.Sc [N] students.

$>$ To find the association between the post-test knowledge regarding utilization of crash cart trolley among III year, B.Sc [N] students with their selected socio-demographic variables.

1. The first objective was to assess the knowledge regarding utilization of crash cart trolley among nursing students:

The mean score was 57\% Correct. Although of intensive care unit nurses correctly identify the equipment's should be measured, only $61 \%$ were able to measure it correctly, and answer to this practical question varied.

2. Second objective was to assess the effectiveness of Structured Teaching Programme on knowledge regarding utilization of crash cart trolley among B.Sc. [N] Nursing student in E.S College of Nursing V.Salai, Villupuram. 
The result shows that $70 \%$ nurses have sufficient skills and 95\% of the nurses have mathematical skills. Moreover, 79\% have sufficient knowledge on conversions, solution calculation (50\%), tablet calculation (95\%), weight calculation (77\%), and infusion rate calculation (73\%). The analysis revealed that the youngest nurses (20-29 years) have adequate skills, and where as the oldest (50-59 years) have less skill. According to above study Investigator concludes that the pharmacological skills of the nurses seemed to be inadequate.

3. Third objectives was find the association between the post-test knowledge regarding utilization of crash cart trolley among III Year, B.Sc. [N] students with their selected socio-demographic variables.

Findings of the study revealed that the mean pre-test knowledge scores of nurses on organization of emergency drugs were 22.47, which was found to be inadequate. There was an increase in the post test knowledge after the administration of self-instructional module. An evaluative study was conducted on the effectiveness of self-instructional module on selected drugs used in critical care units. The pre-test mean percentage knowledge of nurses was found to be less than $50 \%(49.92 \%)$. Findings of the study indicated that nurses were not adequately equipped with the knowledge on selected drugs. An increased knowledge score has obtained after the administration of self-instructional module.

\section{CONCLUSION}

The present study assessed the knowledge regarding crash cart trolley in pre-test. After providing structured teaching programme on utilization of crash cart trolley there is a significant improvement on knowledge of students regarding crash cart trolley. The study assessed the knowledge among students and they are gained in knowledge about crash cart trolley. The study concluded that the structured teaching programme was effective in improving in the knowledge regarding crash cart trolley.

Acknowledgement: None

Conflict of Interest: None

Source of Funding: None

Ethical Approval: Approved

\section{REFERENCES}

1. Arkwright TW. A hospital-wide crash cart program. Hosp Mater ManageQ. 1985;7(2): 12-21.

2. Australian college for emergency medicine. Guidelines on emergency department design [homepage on the internet]. 2002 [cited 2012 march 1]. Available from: http://www.acem.org.au/media/ Policies_and_Guidelines/G15_ED_Design.p d.

3. Baker KN, Flynn EA, Pepper GA, Bates DW, Mikeal RL.emergency Medication Error Observed In 36 Health Care Facilities. Achieves of Internal Medicine 2002; 162: 1897-1903.

4. Balasaraswathy (1995). A study to determine the effectiveness of selfinstructional module for nurses on administration of emergency drugs to critically ill patients of selected hospitals in Mangalore. Master science in nursing, Mangalore university.

5. Beate $\mathrm{H}$, Elizabeth J Bridges. Monitoring emergency Intra Arterial Blood Pressure: What You May Not Know. Crit Care Nurs. 2007; 22: 60-79.

6. Begg JE. A pediatric care and resuscitation cart: one community hospital's ED experience. J Emerg Nurs. 1995;21(6):5559.

7. Benhamou-Jantelet G, Héron L, Berrebi D, Veyer K. Emergency crash cart and its use in an academic medical center. Soins. 2007; 714:35.

8. Black JM. Medical surgical nursing. $7^{\text {th }}$ ed. Philadelphia: Elsevier Publications; 2004.

9. Brunner, Suddarth. Textbook of medical surgical nursing. $11^{\text {th }}$ ed. Philadelphia: Lippincott Publishers; 2008.

10. Calvo Macías C, López-Herce Cid J, Carrillo Alvarez A, Burón Martínez E. Material for the pediatric resuscitation trolley. An Pediatr (Barc). 2007;66(1):51-4. 
11. Colquhoun M, Gabbot D, Mitchell S. Cardiopulmonary resuscitation guidance for clinical practice and training in primary care', Resuscitation Council (UK) viewed 21 February 2012, from http://www.resus.org.uk.

12. Cranswick PJ, Rodda M. Box Hill Hospital resuscitation trolley. Anaesth Intensive Care. 1998; 26(2):189-92.

13. Desalu L, Kushimo O, Akinlaja O. Adherence to CPR guidelines during perioperative cardiac arrest in a developing country. Resuscitation. 2006;69(3):517-20.

14. Dyson E, Smith GB. Common faults in resuscitation equipment-guidelines for checking equipment and drugs used in adult cardiopulmonary resuscitation. Resuscitation. 2002;55:137-49.

15. Gabbot D, Smith G, Mitchell S, Colquhoun M, Nolan J, Soar J, et al. Cardiopulmonary resuscitation standards for clinical practice and training in the United Kingdom', Accident and Emergency Nursing. 2005; 13(3):171-9.

16. Ghonaimy S, Khedr Y, Boraei A. Emergency trolleys: available and maintained but are their locations known? 2013.

17. Gladstone J. Drug Administration Errors: A study into the factors underlying the occurrence and reporting of drug errors in a District General Hospital. Journal of Advanced Nursing. 1995; 22:628-637

18. Guy J Persaud J, Davies E, Harvey D. Drug Errors: What Role Do Nurses And crash carts have in minimizing the Risk? Journal of Child Health Care 2003; 7(4): 277-90.

19. Hand $\mathrm{H}$, Banks A. The contents of the resuscitation trolley [published correction appears in Nurs Stand. 2004; 18(47):31]. Nurs Stand. 2004;18(44):43-52. 10.

20. Human Factors: The Journal of the Human Factors and Ergonomics Society December 2011; 53:6626- 36.

21. Jevon P. Standards for clinical practice and staff training in CPR', Nursing Times. 2004; 100(47):28-9.

22. King RL. Nurses perception On Their emergency Educational Needs. Journal of Advanced Nursing 2004; 45(4): 392-400.

23. Makkar $\mathrm{N}$ et al. Int J Res Med Sci. 2016 Sep;4(9):3968-3976 International Journal of Research in Medical Sciences | September 2016 | Vol 4 | Issue 9 Page 3976
24. National Patient Safety Agency of the UK (NPSA), 2008, =Treatment for safety: why we need it. How do we do it', viewed 15 May 2009, from http://www.npsa.nhs.uk/ patient safety/human factors/team working.

25. Nguyen BT. Prise en charge et gestion des cabarets de réanimation par le département de pharmacie. Pharmactuel. 2003;36(1):424.

26. Niemi Hg, Hupli M. Kilpi HL, Puukka P. Medication Calculation Skill of Nurse in Finland. Journal of Advanced Nursing 2003; 12: $519-28$

27. Nolan G, Soar J. guidelines for the Provision of Anesthetic Services. 2013.

28. Nursing Practice Educator Resuscitation. Nurs Times. 230714(30).

29. O'shea E. Factors Contributing To emergency Medication Errors: A Literature Review. Journal of Clinical Nursing 1999; 8: 496-5 04.

30. Patient Safety Bulletin 1. Rapid Learning from reported incidents. NPSA, London July 2005.

31. Process Step Potential Failure Modes Potential Effect on Patient Criticality Root Causes Prevention Strategies. 2002.

32. Rajeswaran L, Ehlers VJ. Audits of emergency trolley's contents in selected hospitals in Botswana', Health SA Gesondheid 17(1), Art. \#621, 7 pages. http:// dx.doi.org/10.4102/hsag. v17i1.621. 2012.

33. Remote Health Atlas, 2007,_Resuscitation trolley. viewed 16 February 2012 from http://remote healthatlas.nt.gov.au/ resuscitation_trolley.pdf.

34. Reprinted article -@2010 Pennsylvania Patient Safety Authority Pennsylvania Patient Safety Advisory. 2010;7(2-June).

35. Resuscitation Guidelines 2010. Resuscitation Council (UK). http://www.resus.org.uk/resuscitationguidelines/.

36. Robin D.Dennison. A Medication safety education programme to reduce the risk of harm caused by medication errors .The Journal of Continuing Education in Nursing2007; 38(4): 176-83.

37. Rozario J.M. a study to Asses the knowledge and practices of Nurses in the Administration of Selected emergency Intravenous drug in Intensive Care units. Master of Science in Nursing Dissertation; 
S. Aruna et.al. A study to assess the effectiveness of structured teaching programme on knowledge regarding utilization of crash cart trolley among III-B.Sc. nursing students at selected college Villupuram

SNDT Women’s University. SNDT College Of Nursing; Bombay, 1994.

38. Sams L. M (1997). Effectiveness of structured SIM on selected drugs used in CCU,for the staff nurses working in these units in selected hospital of Karnataka. Unpublished MSc thesis. Manipal academy of higher education, Deemed University.

39. Shannon Keen. What Are the Contents of an Emergency Cart? [Homepage on the internet]. 1999 [cited 2012 march 4].available from: http://www.ehow.com/ facts_7244281_contents- emergencycart_html 13. Hogh L, Kane L, Bhalla A, Ward MC. Variations in the provision of resuscitation equipment: survey of acute hospitals. Postgraduate Medical Journal. 2005;81(1956):409-10.

40. Sharan D. Repetitive strain injuries. Available from: URL:http://www.emergencymedicinemims. com/articles_details.php?id=16

41. Smith A, Kinross J, Bailey M, Aggarwal R, Toresen, D, Vincent C. Restocking the resuscitation trolley: how good is compliance with checking procedures'? Clinical Risk. 2008;14(1):4-7.

42. Swapna Naskar Williamson. Emergency Nursing: The need for clinical specialization. The Nursing Journal of India April2002; LXXXXIII (4):78-9

43. Vukmir RB. Survival from prehospital cardiac arrest is critically dependent upon response time. Resuscitation. 2006;69(2): 229-34. 2. Telesca K. A simplistic approach to restocking crash carts. Hosp Pharm. 1992;27(12):1068-70,1072.

How to cite this article: S. Aruna, Kalaimathy K., G.Sivasakthi Raman et.al. A study to assess the effectiveness of structured teaching programme on knowledge regarding utilization of crash cart trolley among III-B.Sc. nursing students at selected college Villupuram. Galore International Journal of Applied Sciences \& Humanities. 2021; 5(4): 15-21. DOI: https://doi.org/10.52403/gijash.20211004 